\title{
GAME-BASED WORKSHOPS FOR THE WOOD SUPPLY CHAIN TO FACILITATE KNOWLEDGE TRANSFER
}

\author{
Kogler, C. \& Rauch, P. \\ Institute of Production and Logistics, University of Natural Resources and Life Sciences, Vienna, \\ Feistmantelstrasse 4, 1180 Vienna, Austria \\ E-Mail: christoph.kogler@boku.ac.at, peter.rauch@boku.ac.at
}

\begin{abstract}
Knowledge transfer between science, industry and education is needed to manage complex wood supply chains challenged by increasingly frequent risk events and natural disturbances. Discrete event simulation provides a high potential for stakeholder participation, pedagogical purposes and decision support but simulation models for the wood supply chain are rarely used in industrial training and university education. Consequently, this paper showcases the further development of a scientific discrete event simulation model for the wood supply chain to an intuitively usable workshop edition focusing on game-based design, visualization and animation. Furthermore, a resulting guideline to develop workshop structures consisting of an input, learning by doing and analysing stage including learning objectives is delivered. Presented experiences and feedback of conducted scientific, industrial and educational workshops illustrate the facilitated knowledge transfer. Simplification, visualization and stakeholder collaboration increase model reliability and suitability enabling the dissemination of adapted scientific discrete event simulation models in game-based workshops to sensitize, train and provide decision support for managers, students and researchers.

(Received in June 2020, accepted in August 2020. This paper was with the authors 2 weeks for 2 revisions.)
\end{abstract}

Key Words: Discrete Event Simulation, Logistics, Wood-Based Industry, Decision Support System, Simulation Education; Workshop Design

\section{INTRODUCTION}

The wood supply chain includes growing, harvesting, extraction, transporting, storing, (pre-) processing, (re)using and recycling of wood. Individual actors along this chain optimize their own profit and exchange material, service, financing and information flows on different levels. Therefore, wood supply chain management considers the challenge of competitiveness of the entire supply chain and deals with the relevant decisions to plan, design, operate, control and monitor the chain. Managers try to improve efficiency and resilience from an economic, ecologic and social point of view, but struggle due to the dynamics of networks and complex interdependencies. Consequently, management decisions rely massively on experience and patterns established over time, since information about lead- and queuing times, network capacities and bottlenecks as well as risk management is lacking [1].

Today's wood management students are the wood scientists and industry decision makers of tomorrow. However, in order to meet a variety of job profiles, the curricula of their studies are diverse. This makes it hard for students to gain an overview of the operation research related themes such as optimization and simulation, due to the advanced requirements of mathematics, statistics, coding and abstract thinking. Scientists find it difficult to establish credibility of their models and get them into practical use or provide interfaces to other models because stakeholder are not sufficiently involved in model building, verification and validation processes. Therefore, support for today's (managers) and tomorrow's (students) decision makers by scientists, has to be enhanced by the combination of state-of-the-art methods such as simulation with stakeholder participation in tool development or analyses. Simulation approaches solve real world problems. In particular, discrete event simulation (DES) is a highly suitable method for modelling, mapping and analysing the wood supply chain realistically due to its intermediate 
abstraction level, straightforward model structure, which enables the mapping of business processes, and extendibility with regard to other simulation (e.g., agent based, system dynamics) and optimization approaches [1]. Furthermore, DES-based serious games have a high potential for pedagogical purposes by actively involving stakeholders to experience complex system characteristics within a safe learning environment [2].

Key strategies to facilitate knowledge transfer and exchange were reviewed and include face-to-face exchange in regular meetings, educational sessions, steering committees, webbased information and interactive, multidisciplinary workshops [3]. Pavelin et al. contribute a guideline for running interactive workshops and state that interactive workshops with visual metaphors and games encourage creative problem exploring and solving [4]. Consequently, a game-based workshop design disseminating a scientific DES model has a high potential to transfer knowledge between scientific, industrial and educational stakeholders of the wood supply chain.

The adaption of an earlier introduced DES model [5] allows the development of different workshop designs for scientists, managers and students. This enables a learning process through playing a serious game and analysing the outcome of decisions according to key performance indicators (KPIs) in group discussions. The simulated supply chain extends from forest to industry and covers wood harvesting, forwarding and pre-carriage to a wood terminal, storage, transhipment to rail wagons and final transport to, and unloading at, wood-based industry plants. In order to provide a new intuitive user interface, additional system logic, input masks, detailed animations and visualizations were added to the earlier model. New real-world scenarios provide multiple learnings such as: how to improve business as usual by finding best fits, which new strategies to adopt in the face of changed conditions, and how to manage risks by preparing contingency plans. Furthermore, newly developed specific workshop designs facilitate decision support for managers, provide the means to train students as well as to sensitize researchers on how to deal with challenging supply situations. In the area of wood supply chain research with DES, many articles only include rough explanations and documentations of the simulation model and do not provide access to the model or report on knowledge transfer from science to industry or students [1]. Consequently, this article showcases the benefits of knowledge transfer through game-based workshops based on an adapted scientific simulation model to provide a guideline to disseminate DES models.

In order to address how the design of game-based workshops for specific target groups, based on a scientific DES model for the wood supply chain, can facilitate knowledge transfer from science to industry, science to university education as well as between scientific working groups, the article is divided into the following sections. The literature section (2) discusses related works and points out the research gap. The method section (3) introduces the simulation approach (3.1), scientific simulation model (3.2) and the workshop edition of the simulation model (3.3). The results section (4) depicts workshop structures and designs (4.1) as well as experiences (4.2). Finally, the discussion (5) and conclusions (6) as well as further research opportunities are presented.

\section{LITERATURE}

Literature on the development of workshop designs based on DES models to facilitate knowledge transfer is rare, but experiential learning and gamification, simplification as well as conceptual modelling provide helpful starting points. Despeisse [6] discusses serious games and game-based learning concluding that they stimulate participants, promote deeper learning and enable the application of theories and reflections on the impact of decisions. Van der Zee et al. [7] see simulation model simplification as an underdeveloped topic which needs a way forward to enhance knowledge transfer between stakeholders. Robinson [8] defines conceptual 
modelling as abstraction, implying the need for simplification (i.e., rapid model development/use and to improve transparency) and for assumptions (i.e., limited knowledge or presumptions), of a simulation model from the part of the real world it is representing. Earlier, he defined conceptual modelling formally as a non-software specific description of the computer simulation model describing objectives, inputs, outputs, content, assumptions and simplifications of the model to build valid, credible, feasible and useful models [9]. This builds mainly on the question of Pidd [10], "What is the model used for?", to separate tools for routine decision making (e.g., automation of decision, routine decision support) and tools for thinking (e.g., representing possible system designs and changes, insights for debate, human interaction). Consequently, clearly defined objectives and the level of abstraction with stakeholders involvement prior to the model development as well as efforts to develop straightforward and intuitive controllable simulation models provide a sound basis for knowledge transfer through game-based stakeholder workshops.

In forest management research strengths, weaknesses, opportunities and threats (SWOT) analysis complemented with strategy formulation, structured forecasts relying on expert panels (Delphi method) as well as analytic hierarchy processes (AHP) have been the main methods for stakeholder participation [11-13]. Moreover, actors have been involved in research projects through interviews or case studies in order to provide data to solve a specific problem setting $[14,15]$ or workshops for back-casting or scenario development and design. In other research communities there exist already valuable examples for facilitated modelling $[16,17]$. Earlier studies on simulation education facilitating knowledge transfer focused on course designs for one class or audience and the teaching of simulation model development [18-22]. Works providing comparisons are only available for teaching simulation to students at different universities [23]. Furthermore, simulation games were developed to motivate students and teach special principles [24-26]. Successful examples in the wood supply chain research are the freely available and prize-winning online wood supply game, which is an adaption of the Beer game [27], as well as the transport game [28]. They teach supply chain challenges such as bottlenecks, system capacities, burdens of the bullwhip effect, and hierarchical procurement planning. Conversely, the integration of professionally developed, adapted, scientific simulation models in workshops is rarely discussed. Consequently, this article aims to fill this research gap.

\section{METHOD}

\subsection{Simulation approach}

Simulation approaches are highly useful for cases where analytical calculations are complex or not expedient and experiments with real objects are difficult or not possible due to expense, danger, inefficiency or duration. Moreover, simulation provides straight forward decision support, is highly suitable for strategy evaluation based on various scenarios and facilitates a deeper understanding of the reality modelled. Contemporary software systems support the commonly applied simulation approaches such as DES, agent-based simulation and system dynamics, and some even allow one to combine them. System dynamics simulates continuous systems, whereas DES and agent-based simulation are discrete. Tako and Robinson [29] compared system dynamics and DES in the supply chain context and found no evidence that SD was used more for strategic problems (as often stated) and DES for operational/tactical ones. For deeper insight into the mentioned simulation approaches, refer to [30] and for practical guidelines to develop multi-method simulation models, refer to [31] and [32]. The DES approach is highly appropriate to investigate the wood supply chain and therefore, was intensively used in literature $[1,33,34]$. DES is dynamic (i.e., variables change over time) and stochastic (i.e., random observations) and can be combined with other simulation and optimization approaches. Especially for stakeholder participation, this approach is superior to 
others because of its straightforward model structure enabling business process mapping, which is well-known and well received by scientists, managers and students. It allows one to model, map and analyse complex interdependencies of the wood supply chain close to reality. Moreover, it visually illustrates model internals (e.g., process flows, statistical counters, decision rules, system configurations) in animations to stakeholders. To evaluate effects of decisions before real, costly system changes are made, results for different supply strategies or supply chain designs and what-if analysis can be compared. This contributes to a better understanding and provides practical and useful decision support of the wood supply chain.

\subsection{Simulation model}

As a basis for the simulation model development a comprehensive case study was conducted from 2016 to 2018. The focus was on a multimodal wood supply chain in Austria including one of the 150 Austrian rail terminals for wood in order to observe an innovative multimodal system, which increases the buffer capacity, improves resilience and reduces emissions. The investigations included interviews with forest owners, truck and rail carriers, terminal managers, wood supply managers, wood traders and industry managers as well as data collection which was supported by the Rail Cargo Austria, Austrian Federal Forests (AFF), Central Agency for Meteorology and carriers. This set the stage for business process, information flow, material flow and risk event mapping, which supported the simulation model development. Three regional truck carriers transport between 2,000 to 30,000 cubic meters of wood per month from four supplying forest districts of the AFF to the observed train terminal in the Styrian village Großreifling. Furthermore, they tranship the wood directly to train wagons or to the stockyard, where up to 10,000 cubic meters can be stored. Once or twice a day a locomotive delivers required empty wagons and collects full ones. Rail terminals in Austria play a significant role after natural disturbances such as windstorms, when high volumes of salvage wood have to be transported in a short period of time to avoid bark beetle infestations. Up to now, no contingency plans have been developed. Consequently, after a storm, managers apply an expensive and inefficient trial and error system to figure out a smooth working system configuration (e.g., number of trucks, number of wagons, timing of train pickups, harvesting volumes) to overcome the specific supply chain challenges such as truck transport capacity bottlenecks or dramatically rising lead times and waiting times at wood-based industry plants.

The scientific simulation model consists of forest-, truck transport-, train transport-, industry- as well as terminal modules. Wood entities are generated in four different sources representing the four case study districts in the forest module. After wood is cut, forwarded, stored at forest landings and batched into truckloads, it either goes via the truck transport module directly to the industry module (i.e., unimodal transport) or first to the terminal module and then to the train transport module before it reaches the industry module (i.e., multimodal transport). The truck transport module generates truck entities and controls their behaviour during their working times within the network by sending unloaded trucks to pick up jobs in the forest or to transhipment jobs at the train terminal. Since the simulation focuses on the train terminal, the processes in the terminal module are modelled in great detail and cover the following activities: removing safety belts, loading wagons, securing wagon loads, unloading at stockyard, cleaning platforms and completing delivery notes. Therefore, the terminal module contains a complex logic controlling the transhipment process from trucks to respective stockyards to train wagons as well as the potential truck queuing at the terminal. The train module generates train entities, which pick up fully loaded wagons, transports them to industry, leave empty wagons for loading and sort wagons according to their loading status at the terminal. In the industry module, the unloading process is modelled in wood-based industry plants. For a detailed description of an earlier DES model, which was build for the scientific purposes to compare unimodal and multimodal refer to [5]. To provide a sound basis for 
decision making and to establish credibility, substantial time and effort was invested in the verification and validation process of the simulation model development. Professional and scientific experts were involved regularly in step-by-step walkthroughs and discussions on core assumptions. To enable deeper insight, detailed animations and visualizations of critical processes in business process diagrams were used. Moreover, modular design, component testing and code reviews by teams ensured high quality coding. Frequent reruns of experiments, model runs under simplified assumptions as well as extreme scenarios were the basis of detailed output checks. Finally, experts confirmed the results both in industry and scientific workshops.

\subsection{Workshop edition}

The new workshop edition of the simulation model enables the management of the supply chain and the observation of the current process flows and their resulting statistics. Therefore, the supply chain view (Fig. 1) provides a good overview of the chain and enables observing wood, truck and train entity flow through the system during runtime. Complex queuing problems can be observed and analysed in the terminal view (Fig. 2).

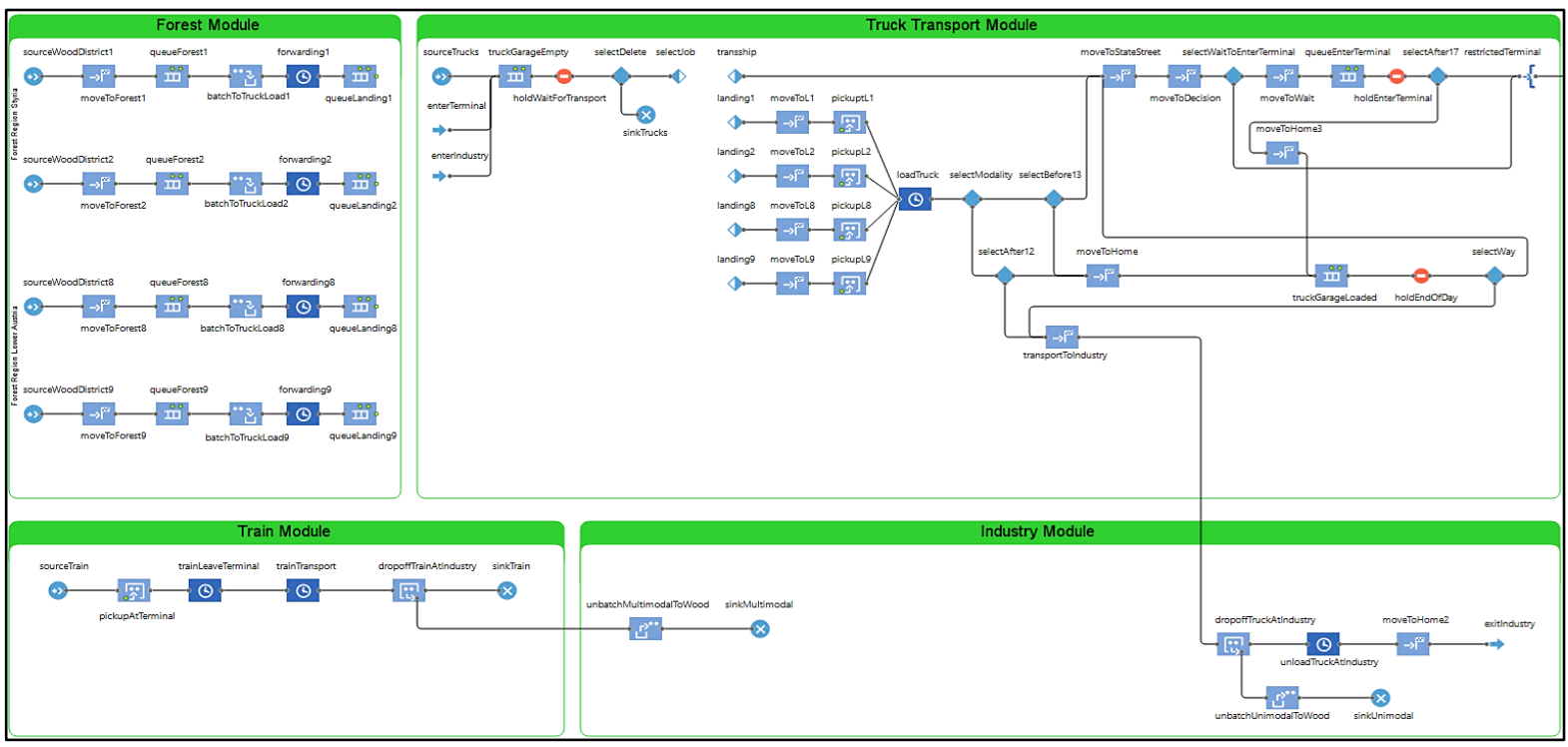

Figure 1: Supply chain flow chart.

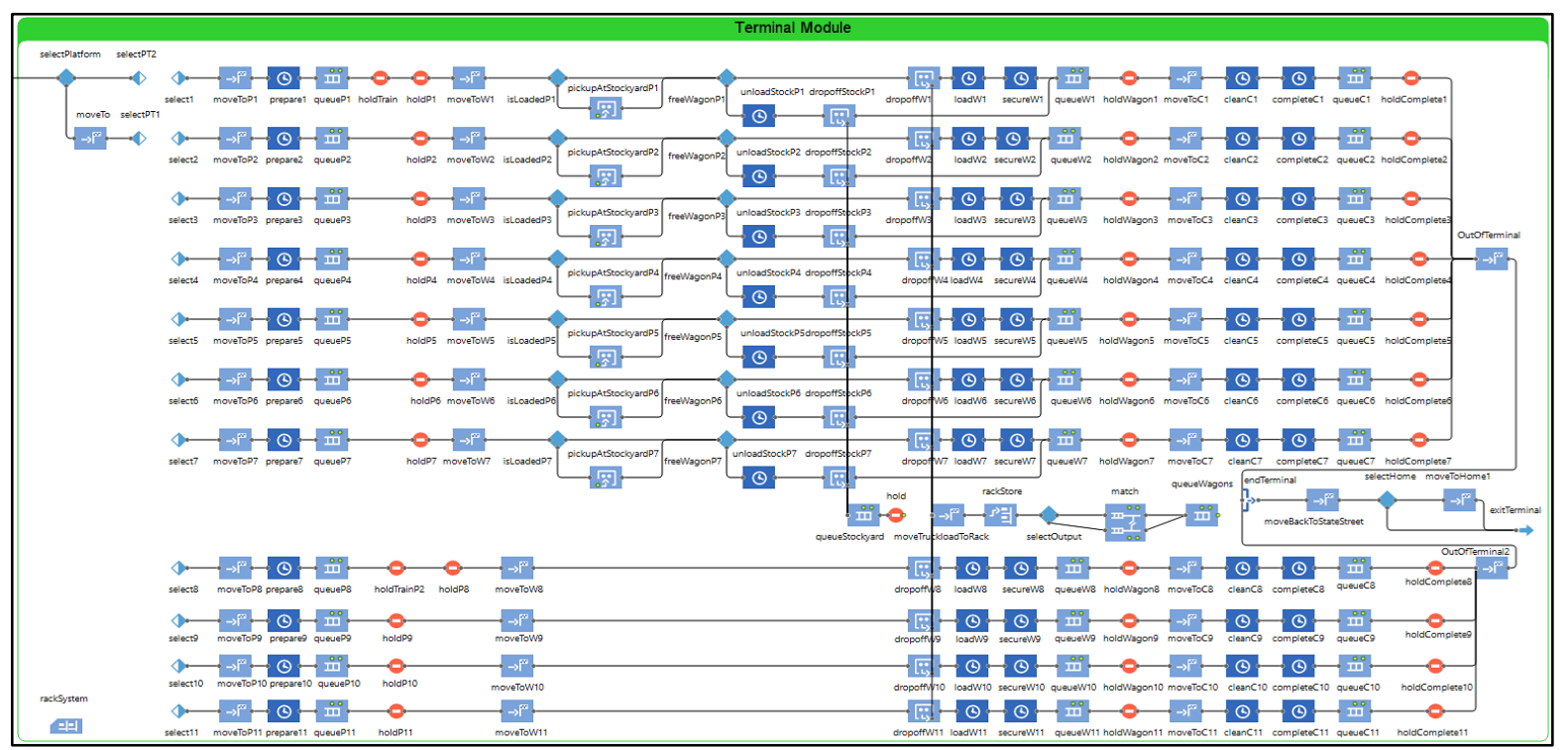

Figure 2: Terminal flow chart. 
Current values of implemented statistical counters, functions, variables, data sets, parameters, schedules and events can be monitored in the code and statistical data view. Thus, this views support workshop participants to analyse the current and past status of the supply chain in detail and encourages data-based transport planning decisions. The workshop control view (Fig. 3) shows the harvesting volumes for each region for the upcoming week (A) as well as the harvesting volumes of the past weeks (B). Furthermore, the transport plan for the upcoming week can be defined. The number of train wagons can be chosen between 0 and 9 (1) with one or two train pickups per day (3). The number of trucks can be selected (2) between 0 and 50. The transport mode split (4) allows the definition of a strategy regarding the percentage of multimodal as well as unimodal transports. The transport priority (5) defines whether trucks should pick up wood from the largest stock or the oldest wood first. After the situation of the supply chain is analysed and the transport plan and strategy for the upcoming week is selected, the simulation for the next week starts (6). It is possible to jump directly to the next week (virtual speed) or to lower the speed to observe the process flows or the KPI changes during runtime.

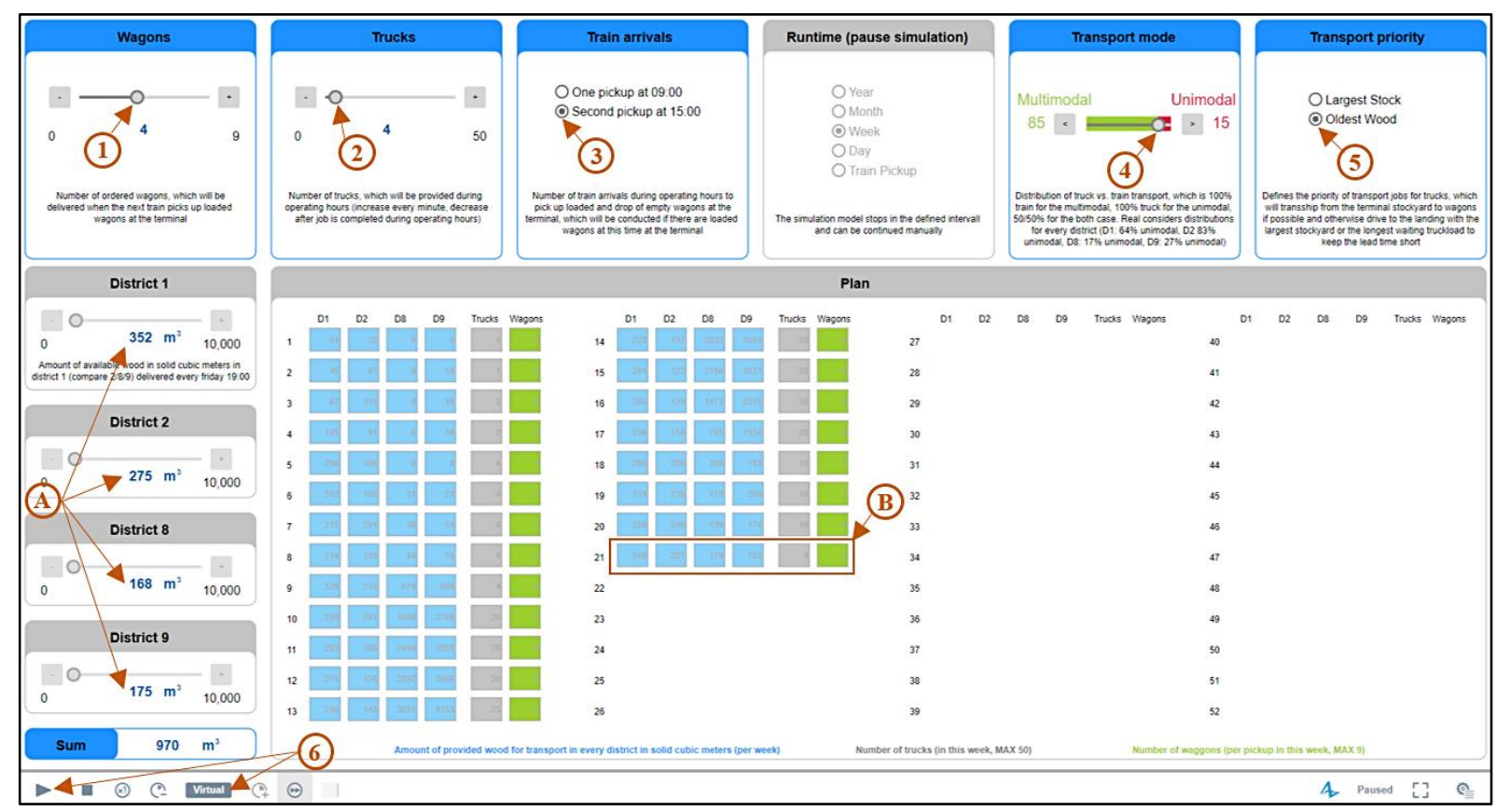

Figure 3: Workshop control view.

\section{RESULTS}

\subsection{Workshop structure}

The DES model's workshop edition provides a wide range of potential applications. Therefore, a generic structure of workshops for students, scientists and managers sets the basis for the development of a variety of specific workshop designs. Consequently, workshop design has to be customized to participants' needs. As a first step, the general aims of the workshop have to be discussed in order to derive, formulate and define concrete learning objectives based on the revision of Bloom's taxonomy. In a second step, methods and exercises contributing to achieve the aspired targets have to be chosen. In a third step, the actual content, setting, schedule and scenario needs to be designed with a focus on addressing the topic in the most visual way possible. The generic workshop structure consists of three stages for input, learning by doing and analysis to facilitate knowledge transfer to mangers, students and scientists. Depending to the available time, each stage will last between 30 and 60 minutes. 
The input stage starts with a brief overview of the workshop agenda and answers any initial questions from participants such as, "Why are we here?". Consequently, the problem setting and goals need to be defined. The goals for a scientific workshop (e.g., explain the potential of the DES method to colleagues) differs from those of industrial training (e.g., provide decision support for a specific problem setting to managers) or university educational (e.g., provide insights to a specific wood supply chain and common supply chain challenges), however, the problem settings can be similar for them all. Possible problem settings could include the following: to improve business as usual by finding best fits for planned harvesting volumes and industry's transport orders according to given KPIs, to prevent bottlenecks, to test new strategies responding to changed conditions, and to see the effects of decisions before real, costly system changes are made. Further problem settings include risk management by preparing contingency plans for natural disasters, delivery stops at mills, machine breakdowns or legislative changes. Moreover, the case study setting of a multimodal wood supply chain should be briefly explained. This allows one to guide the participants to the question, "How can we experience, observe or analyse the problem?". Here, the workshop edition of the scientific DES model takes the stage and needs to be explained. At first, the different views are introduced with screenshots. Different applications of the simulation model are then shown in a live demonstration. This includes the illustration of the process flow of a day, week, month or year as well as the change of KPIs. More experienced users and scientists may also be interested in the Excel data import and export option as well as in the comparison of different simulation experiments. After this general tutorial, the handling of the workshop control view (see Fig. 3) of the workshop edition is explained in detail.

At the beginning of the learning by doing stage the problem setting is clearly defined (e.g., manage the transport planning for the first half of the year by using the available transport capacities). This can be supplemented by hints (e.g., observe the outcomes of your strategies in the statistical data view before you decide on the strategy of next week). Then the participants get hands-on experience of the DES model's workshop edition in small groups from 3 to 5 people, depending on number of participants and available simulation computers. The groups play the defined simulation scenario (i.e., system capacities, period, harvesting volumes) and discuss their strategies. For every simulated business week, each group has to decide on the transport plan for the upcoming week based on stockyard utilization, harvesting volumes as well as other KPIs (e.g., number of trucks, wagons, train pickups, unimodal/multimodal ratio and transport strategy). All KPIs are logged during the game and automatically exported to an Excel file to provide a sound basis for the last stage.

The analysis stage starts with a progress report where every group describes their strategies, problems, solutions and findings. After their statements, the workshop coordinator presents the scenario settings and explains the production pattern (e.g., simulation of a storm scenario where the production amount increases dramatically). Moreover, a variety of KPIs such as lead times, queuing times, stockyard sizes, transport volumes, truck utilizations, $\mathrm{CO}_{2}$ emissions, delivery quotas, number of full loaded wagons, fulfilment levels or transport costs are compared over time and between groups in different graphs. Depending on the group participation level, this can be a good start for a deep discussion of observed findings. In addition, follow up workshops in world café or open space settings are possible to further develop ideas, since the game playing experience enhances the willingness of participants to create radical solution. The discussion is wrapped up by documenting results and drawing conclusions. Finally, next steps to tackle outstanding and arisen challenges are defined before the stage closes with a feedback session.

\subsection{Experiences}

Observations of first workshops showed that students and scientists are faster than managers in acquiring skills to handle and operate the simulation model, but wood supply chain managers 
needed far less time to decide on weekly transport plans. This can be explained by more transport planning experience of managers, which is a task of their daily business. Moreover, managers and industry experts outperformed others regarding many KPIs due to their longstanding experience working with multimodal wood supply chains. In some of the conducted industry workshops, it emerged that the workshop edition of the scientific model still offered too many parametrization options and that this had the potential of confusing participants rather than providing additional value.

Critical feedback from scientists, managers and students was analysed, implemented and inspected in recurring workshops. Scientific colleagues with a similar research focus gave constructive feedback to add additional scenarios, which was realized by providing built-in business as usual, wind throw (i.e., high production) and heavy snow fall (i.e., low production) scenarios and the option to create new scenarios in Excel and import parameters within the user interface of the simulation model. Another recommendation regarded adding further transport strategies. Therefore, the option was implemented to define the amount of multimodal and unimodal transported wood with a slide bar. Moreover, pick-up options of trucks to either collect the oldest wood pile or the largest wood pile first were developed and offer the user additional decision options. Managers gave valuable feedback in terms of a more realistic system configuration. As a consequence, the maximal number of available trucks was adjusted.

In one of the first workshops, industry experts encouraged to develop an export option for main KPIs to Excel, which was implemented to provide easy handling of simulation results for different scenarios. In addition, managers were interested in improving business as usual at the case study terminal or similar terminals in Austria. This can be achieved by adapting the parameterization of the simulation model in the comprehensive parameterization view of the user interface. Furthermore, they requested further workshops to prepare realistic contingency plans and guidelines for different extreme scenarios. Students remarked on the need to develop a clear, intuitive layout of the user interface and to concentrate on the most important KPIs to enable a high usability. In addition, they recommended support for special use cases (e.g., how to reduce stock levels at the terminals, reduce queuing time or increase truck utilization), which were included in the live demonstrations of the input stage of the workshop.

\section{DISCUSSION}

The first workshops were delivered to scientists, industry managers and students to test and enhance workshop designs. Each target audience was split in two levels of mastery according to their experience in wood supply chain management. This resulted in six workshops for different numbers of groups (i.e., each group 2 to 5 people, depending on the number of participants) which were similarly structured. Scientific workshops were held for three groups with low levels of experience from the Institute of Production and Logistics of the University of Natural Resources and Life Sciences, Vienna and two highly experienced groups from the international research project MultiStrat including participants from Norway, Sweden and Austria. Industry workshops have been concluded with one group of low experience managers of AFF and three groups of highly experienced wood logistic managers of AFF. Educational workshops have been held for two groups of low experience undergraduate students and four groups of highly experienced master students. Learning objectives (1-8) were defined and classified in Table I according to the revision of Bloom`s taxonomy [35]. While the first six learning objectives are relevant for all three target audiences, the seventh objective is mainly relevant for industry managers and the eighth mainly for scientists:

1. Remember the material flow between different actors with specific interests of a wood supply chain. 
2. Explain the principles and the suitability of the method DES to model interrelations among basic system elements of the wood supply chain.

3. Demonstrate the operation of the workshop edition of a scientific DES model and illustrate the handling of different views.

4. Analyse influences of decision variables on KPIs.

5. Discuss and evaluate different strategic options to meet defined goals for selected KPIs.

6. Develop transport plans and define new strategies.

7. Manage risks of natural disasters by preparing guidelines for contingency plans.

8. Create new DES models or combine existing models through interfaces.

Table I: Classification of learning objectives based on the revision of Bloom's taxonomy.

\begin{tabular}{|c|c|c|c|c|c|c|}
\hline & \multicolumn{6}{|c|}{ Cognitive process } \\
\hline Knowledge & remember & understand & apply & analyse & evaluate & create \\
\hline factual & 1 & & & & & \\
\hline conceptual & & 2 & & & & \\
\hline procedural & & & 3 & 4 & 5 & $6,7,8$ \\
\hline metacognitive & & & & & & \\
\hline
\end{tabular}

Evaluation of initial workshop designs through qualitative feedback sessions gave an impression of what succeeded and what needed rectification. Therefore, various qualitative feedback methods such as written feedback/protocols, participant observations, in-depth interviews, open round- as well as focus group discussions were used. Managers and researchers were invited to deliver a critical written feedback after the workshop and students had to submit a written protocol about the workshop and their experiences with the workshop edition of the simulation model. Moreover, experienced coaches and teachers observed the participants behaviour during the workshop, noted their impressions and communicated a reflection. Furthermore, in-depth interviews were conducted with selected participants to observe their imaginations before and experiences after the workshop. In a final open discussion round verbal feedbacks were collected of every group as well as on an individual level.

So far, the workshop edition of the scientific DES model has been well received by scientists, managers and students. In particular, the detailed visualization of process flows in different speed modes impressed users and allowed them to get a fast overview (e.g., wood production, wood transport, transhipment at a terminal) of the wood supply chain and to concentrate on dealing with actual challenges (e.g., stock levels, truck utilization, truck queuing at the terminal). The intuitive handling of the different views supported their ability to get a complete and deep insight on interdependences of transport capacity, transport modes and supply chain stocks. Furthermore, the provided statistics during runtime fascinated stakeholders. For the first time, they could immediately experience the impacts of extreme scenarios and decisions on important KPIs such as lead time for wood from forest landing to industry or queuing time of trucks at a terminal. Furthermore, they pointed out that for some KPIs (e.g., lead time, terminal queuing time) no reliable real data is currently available in Austria and simulation results provided first realistic numbers.

In scientific workshops, deeper insights in the development of DES models including a scientific literature overview, theoretical aspects, differentiation with other simulation or optimization methods and available software alternatives was additionally provided in the first stage. In university education workshops, the second stage was extended to build a ranking based on predefined KPIs, which motivated students to perform additional scenario runs and learn from other groups in order to outperform them. In contrast to other workshops, the analysis stage lasted up to three hours in industry workshops because managers were able to address problems and challenges in the entire supply chain and to discuss different solution strategies. This highlights the fact that different target audiences need very specific workshop 
designs based on rather similar structure, but with an individual focus depending on the varying interests and professional background of the participants.

This paper provides a guideline to develop and disseminate scientific DES models to facilitate knowledge transfer between science, industry and education. Therefore, it showcases how a scientific simulation model (3.1) was adapted to a workshop edition (3.2) and how gamebased workshops were structured (4.1) to archive hands-on experiences (4.2). Feedback was critically discussed and learning objectives were defined to pave the way for further developments of game-based discrete event simulation workshops in future.

\section{CONCLUSIONS}

The dissemination of an adapted scientific discrete event simulation model in game-based workshops allows scientists, managers and students to gain deep insights into the complexity of the wood supply chain supporting cooperation, credibility and simplification. Scientific colleagues are provided with a fast overview of the most important challenges of the supply chain which facilitates collaboration within and between disciplines. Interfaces to other models can be discussed and input/output data can be defined. Therefore, this simulation model created a co-operation between those scientists and managers who were focused on wood quality development. Existing forecast models covering bark beetle population dynamics and models forecasting wood moisture development and blue stain infection of logs were combined with the supply chain model to facilitate various management responses to wood quality development. Industry co-operation was initiated as managers found starting points for further developments (e.g., terminal layout, transhipment from forest trucks equipped with a crane to trailer trucks). Moreover, the detailed visualizations and animations as well as output checks facilitate stakeholder involvement in the verification and validation process and therefore establishes a high level of reliability and credibility within industry, science and education.

Critical feedback from scientists (e.g., new/other transport strategies, model control options, system configurations), managers (e.g., risks and bottlenecks, terminal layouts, realistic contingency planning) and students (e.g., usability, graphical user interface, scenario designs) was analysed, implemented and inspected in recurring workshops. The commitment to use the workshop edition in university education encouraged to consider simplification wherever possible and implement an intuitive control logic and usability, which further enhanced the model quality. The adaption of a scientific simulation model in an early development stage to a workshop edition supported by stakeholder involvement increases model reliability and the model's suitability to address real world challenges.

In order to further facilitate knowledge transfer and get additional feedback to refine the workshop design, additional workshops were prepared and planned for late 2020. This includes scientific workshops for participants from international research projects, industry workshop for Austrian wood-based industry stakeholders and educational workshops embedded in university courses. To reveal the potential for further developments, classify group results as well as to document the fulfilment of learning objectives, a questionnaire was developed and will be used in the feedback sessions of future workshops.

Future research on next level DES models would benefit from visualization, simplification and stakeholder collaboration at early development stages. More sophisticated simulation software enables the creation of even easier-to-use simulation models, which should be made available to the general public to facilitate sensitizing, training and providing decision support for managers, students and researchers. Research on knowledge transfer and game-based workshop designs including reports about experiences and feedback enables to shift the purpose of next level DES models from mainly scientific use to knowledge transfer between science, industry and education. 


\section{ACKNOWLEDGEMENT}

The authors gratefully acknowledge that this research was funded within the GreenLane (ForestValue Joint Call 2017) project by the Austrian Federal Ministry of Agriculture, Regions and Tourism. Both co-authors participated in funding acquisition, investigation, workshop conduction, interpretation of results, validation, review and editing. Christoph Kogler contributed conceptualization, methodology, literature review, formal analysis, software, visualization, writing and original draft preparation. Peter Rauch provided supervision and project administration.

\section{REFERENCES}

[1] Kogler, C.; Rauch, P. (2018). Discrete event simulation of multimodal and unimodal transportation in the wood supply chain: a literature review, Silva Fennica, Vol. 52, No. 4, Paper 9984, 29 pages, doi:10.14214/sf.9984

[2] Van der Zee, D.-J.; Holkenborg, B.; Robinson, S. (2012). Conceptual modeling for simulationbased serious gaming, Decision Support Systems, Vol. 54, No. 1, 33-45, doi:10.1016/j.dss.2012.03.006

[3] Mitton, C.; Adair, C. E.; McKenzie, E.; Patten, S. B.; Perry, B. W. (2007). Knowledge transfer and exchange: review and synthesis of the literature, The Milbank Quarterly, Vol. 85, No. 4, 729-768, doi:10.1111/j.1468-0009.2007.00506.x

[4] Pavelin, S.; Pundir, S.; Cham, J. A. (2014). Ten simple rules for running interactive workshops, PLOS Computational Biology, Vol. 10, No. 2, Paper 1003485, 5 pages, doi:10.1371/ journal.pcbi.1003485

[5] Kogler, C.; Rauch, P. (2019). A discrete-event simulation model to test multimodal strategies for a greener and more resilient wood supply, Canadian Journal of Forest Research, Vol. 49, No. 10, 1298-1310, doi:10.1139/cjfr-2018-0542

[6] Despeisse, M. (2018). Games and simulations in industrial engineering education: a review of the cognitive and affective learning outcomes, Proceedings of the 2018 Winter Simulation Conference, 4046-4057, doi:10.1109/WSC.2018.8632285

[7] Van der Zee, D.-J.; Tako, A.; Robinson, S.; Fishwick, P.; Rose, O. (2018). Panel: education on simulation model simplification - beyond rules of thumb, Proceedings of the 2018 Winter Simulation Conference, 3987-4001, doi:10.1109/WSC.2018.8632544

[8] Robinson, S. (2011). Choosing the right model: conceptual modeling for simulation, Proceedings of the 2011 Winter Simulation Conference, 1423-1435, doi:10.1109/WSC.2011.6147862

[9] Robinson, S. (2008). Conceptual modelling for simulation Part I: definition and requirements, Journal of the Operational Research Society, Vol. 59, No. 3, 278-290, doi:10.1057/ palgrave.jors. 2602368

[10] Pidd, M. (2009). Tools for Thinking: Modelling in Management Science, $3^{\text {rd }}$ edition, Wiley, Chichester

[11] Brunnhofer, M.; Gabriella, N.; Schöggl, J.-P.; Stern, T.; Posch, A. (2020). The biorefinery transition in the European pulp and paper industry - a three-phase Delphi study including a SWOTAHP analysis, Forest Policy and Economics, Vol. 110, Paper 101882, 12 pages, doi:10.1016/j.forpol.2019.02.006

[12] Rauch, P.; Wolfsmayr, U. J.; Borz, S. A.; Triplat, M.; Krajnc, N.; Kolck, M.; Oberwimmer, R.; Ketikidis, C.; Vasiljevic, A.; Stauder, M.; Mühlberg, C.; Derczeni, R.; Oravec, M.; Krissakova, I.; Handlos, M. (2015). SWOT analysis and strategy development for forest fuel supply chains in South East Europe, Forest Policy and Economics, Vol. 61, 87-94, doi:10.1016/j.forpol.2015.09.003

[13] Rauch, P. (2007). SWOT analyses and SWOT strategy formulation for forest owner cooperations in Austria, European Journal of Forest Research, Vol. 126, No. 3, 413-420, doi:10.1007/s10342$\underline{006-0162-2}$

[14] Eriksson, A.; Eliasson, L.; Sikanen, L.; Hansson, P.-A.; Jirjis, R. (2017). Evaluation of delivery strategies for forest fuels applying a model for weather-driven analysis of forest fuel systems (WAFFS), Applied Energy, Vol. 188, 420-430, doi:10.1016/j.apenergy.2016.12.018 
Kogler, Rauch: Game-Based Workshops for the Wood Supply Chain to Facilitate Knowledge ...

[15] Kogler, C.; Rauch, P. (2020). Contingency plans for the wood supply chain based on bottleneck and queuing time analyses of a discrete event simulation, Forests, Vol. 11, No. 4, Paper 396, 23 pages, doi:10.3390/f11040396

[16] Kotiadis, K.; Tako, A. A. (2018). Facilitated post-model coding in discrete event simulation (DES): a case study in healthcare, European Journal of Operational Research, Vol. 266, No. 3, 11201133, doi:10.1016/j.ejor.2017.10.047

[17] Robinson, S.; Worthington, C.; Burgess, N.; Radnor, Z. J. (2014). Facilitated modelling with discrete-event simulation: reality or myth?, European Journal of Operational Research, Vol. 234, No. 1, 231-240, doi:10.1016/j.ejor.2012.12.024

[18] Martin, N. (2018). Bridging students to practice: performing a real-life simulation study in an introductory simulation course, Proceedings of the 2018 Winter Simulation Conference, 40144025, doi:10.1109/WSC.2018.8632512

[19] Garica, H.; Centeno, M. A. (2009). S.U.C.C.E.S.S.F.U.L.: a framework for designing discrete event simulation courses, Proceedings of the 2009 Winter Simulation Conference, 289-298, doi: 10.1109/WSC.2009.5429339

[20] Freimer, M.; Schruben, L. W.; Roeder, T. M.; Standridge, C. R.; Harmonosky, C. M.; Stahl, I. (2004). You are going to teach simulation - now what? Tips and strategies, Proceedings of the 2004 Winter Simulation Conference, 2057-2065, doi:10.1109/WSC.2004.1371570

[21] Saltzman, R. M.; Roeder, T. M. (2013). Perspectives on teaching simulation in a college of business, Proceedings of the 2013 Winter Simulations Conference, 3620-3629, doi:10.1109/ WSC.2013.6721723

[22] Roeder, T. M. K.; Miyaoka, J. (2015). Using simulation as a teaching tool in an introductory operations management course, Proceedings of the 2015 Winter Simulation Conference, 34813489, doi:10.1109/WSC.2015.7408508

[23] Giabbanelli, P. J.; Mago, V. K. (2016). Teaching computational modeling in the data science era, Procedia Computer Science, Vol. 80, 1968-1977, doi:10.1016/j.procs.2016.05.517

[24] Crookall, D. (1990). Fish Banks, Ltd. (Review), Simulation \& Gaming, Vol. 21, No. 2, 208-211, doi:10.1177/1046878190212011

[25] Showers, J. L. (1977). An inventory management simulation game, Proceedings of the 1977 Winter Simulation Conference, 279-284

[26] Miller, J. (1973). Instructions for Group Session on the Hand Simulation Game: Memo D-1867, MIT System Dynamics Group, Cambridge

[27] D’Amours, S.; Marier, P.; Rönnqvist, M.; Azouzi, R.; Fjeld, D. (2017). Game - the online Wood Supply Game, INFORMS Transactions on Education, Vol. 18, No. 1, 71-87, doi:10.1287/ited.2017.0174

[28] Abasian, F.; Rönnqvist, M.; Marier, P.; Fjeld, D. (2020). The Transportation Game, INFORMS Transactions on Education, in press, 12 pages, doi:10.1287/ited.2019.0223

[29] Tako, A. A.; Robinson, S. (2012). The application of discrete event simulation and system dynamics in the logistics and supply chain context, Decision Support Systems, Vol. 52, No. 4, 802815, doi:10.1016/j.dss.2011.11.015

[30] Law, A. M. (2015). Simulation Modeling and Analysis, $5^{\text {th }}$ edition, McGraw-Hill, New York

[31] Borshchev, A. (2013). The Big Book of Simulation Modeling: Multimethod Modeling with AnyLogic 6, AnyLogic North America, Chicago

[32] Mahdavi, A. The Art of Process-Centric Modeling with AnyLogic, from https://www.anylogic.com/resources/books/the-art-of-process-centric-modeling-with-anylogic/, accessed on $02-08-2020$

[33] Opacic, L.; Sowlati, T. (2017). Applications of discrete-event simulation in the forest products sector: a review, Forest Products Journal, Vol. 67, No. 3-4, 219-229, doi:10.13073/fpj-d-16-00015

[34] Shahi, S.; Pulkki, R. (2013). Supply chain network optimization of the Canadian forest products industry: a critical review, American Journal of Industrial and Business Management, Vol. 3, No. 7, 631-643, doi:10.4236/ajibm.2013.37073

[35] Krathwohl, D. R. (2002). A revision of Bloom`s taxonomy: an overview, Theory Into Practice, Vol. 41, No. 4, 212-218, doi:10.1207/s15430421tip4104_2 